\title{
Prevalence of Cockroaches in A Private Faculty Building/its Surrounding, with Emphasize on its Vectorial Capacity For Intestinal Parasite, Its Public Health Implication and Comparison of the Performance of several Traditional Baits
}

\author{
Forman E. Siagian, ${ }^{1 *}$ Jessica Livina, ${ }^{2}$ I Made Bayu Surya Dana, ${ }^{2}$ Ekarini Daroedono, ${ }^{3}$ Ronny ${ }^{1}$
}

\begin{abstract}
Cockroach caused intestinal problem due to its mechanical vectorial capability. It can carry many parasites, with diverse susceptibility patterns. Its number in the enviromenment determine the potential risk of health hazard to human. This cross-sectional, entomological survey-study aimed to determine its prevalence with emphasize on vectorial capability, public heath implication and comparison of several traditional baits/ attractants used to trapped cockroach. During 4 months of sampling, 434 cockroaches were successfully trapped, and the prevalence of intestinal parasite isolated was $77.9 \%$, which comprise of several types of parasite. Cockroach also more attracted to brown sugar used as baits/attractants. These findings confirmed the importance of keeping hygiene/sanitation practices that must be maintain all the time.
\end{abstract}

Keywords: brown sugar, protozoa, helminth, hygiene, atractants

Among all of household pests, cockroach still considered as the most potential contributor to health hazard- individually or even for public, due to its mechanical vectorial ability. ${ }^{1-3}$ It can carry many type of pathogenic microorganisms, e.g. protozoa, helminth, yeast/fungus and or bacteria. ${ }^{4-6}$ Its ability to carry many kind of pathogens make them unique and important from the community health perspective because this insect relatively have a very close encounter with human. ${ }^{7-9}$ While carrying the seeds of disease on the surface of their body, it then 'un-intentionally' could contaminate the food which was not handled properly, e.g the food was let open for a certain time. ${ }^{7,810}$ Its ability to transmi and causing infectious intestinal problems were still raising our concern, especially in places with poor hygiene practice. ${ }^{11-13}$ These type of food-borne

\footnotetext{
* Corresponding Author : Email: formanerwin@yahoo.com

1 Department of Parasitology Faculty of Medicine Universitas Kristen Indonesia

2 Medical student, Universitas Kristen Indonesia,

3 Department of Public health Faculty of Medicine Universitas Kristen Indonesia
}

disease could be fatal and lethal, especially for vulnerable people. ${ }^{15-18}$

This insect is commonly found inside a building. ${ }^{19,20}$ The morphology of cockroach is unique in appearance. Their shape in general described as follows: its body is oval and flattened dorsoventrally, coloured light brown to black, have two pairs of thin and transparent membranous wings which folded flat over the back- eventhough most species of cockroaches seldom fly, it have the ability to move in a 'fast-mode' due to its six legs, and their body-lengths varied, ranging from the smallest $2 \mathrm{~mm}$ to the largest of $>80 \mathrm{~mm}$ and with its antennae is almost the same length as its body. ${ }^{4}$ These body features helped them to adapt easily. ${ }^{1}$ Their food seeking activity, in order to fulfill their nutritional needs e.g. for growing and mating, determine their food preference. ${ }^{5,11}$ While wandering for food, especially in a dirty place, its body might have contact with many typr of infectious agents. ${ }^{21-23}$ These enviroment- derived microorganisms have diverse sensitivity/susceptibility patterns to antibiotics or antimicrobes, some of them are resistant strain. ${ }^{21}$ It is of particular concern, 
especially from the public health aspect. .,7,18,19,23 $^{6}$

Cockroaches found all over the world and their existence can be traced to the ancient age- more than 300 million years ago- with little or even no modification at all. ${ }^{4}$ The most common species are belong to the genus of Periplaneta and Blatta, named Periplanetta americana, the American cockroach and Blattella germanica, the German cockroach. ${ }^{4,23}$ Both species found abundantly in most parts of the world. With about 3500 known species but only a few are of importance to the human health aspect due to their adaptiveness to living in buildings; and as a consequence cockroach have a relative closed contact with human, especially in poor housing area with neglected waste water management. ${ }^{19,20,22}$ Vulnerable groups in communities such as children, pregnant women, the elderly and refugees are examples of which are at risk of getting infected with these food-borne pathogens carried by cockroach. ${ }^{1,7}$

According to their activity, all cockroaches are nocturnal organisms, and they tend to avoid human; except that it might appear in the daytime only when excessive number in population occured massively or when something disturbed their eco-system. ${ }^{6-8,17}$ Most of these species are found in the tropics and subtropical regions, with preference to live in the dark and relative warmth milleu and also with higher humidity; e.g. any places related or connected with waste water such as waste water pipe, cesspits, septic tanks, sewers, rubbish dumps, refuse tips, dustbins and cupboards, drawers, underneath chairs, tables, water-sinks, water-baths and beds, behind refrigerators, cooking stoves, among (dirty) stacked dishes and even in almost any dark place available. ${ }^{1-}$ ${ }^{6}$ all of these related to their nitrogen metabolism, and their needs of this macro-nutrient(nitrogen) and other type of micro-nutrient and other electrolyte can be fulfilled thru waste water. ${ }^{17}$

The association of cockroaches with various enteric pathogens, especially food-borne parasite, e.g protozoan and helminths, and also with bacterial pathogens have been extensively reported, but their prevalence varied, depend on the location..$^{6,8,18,19}$ The more cockroach available, the bigger the health hazard risk..$^{3,6-9,23}$ So, while doing the entomology survey, the researchers usually also get an overview of public health aspects and hygiene scales of the area being studied. ${ }^{18-21}$
This short study aimed to evaluate the prevalence of cockroaches in a private faculty building and its surrounding, with emphasize on its vectorial capacity for intestinal parasite and comparison of several traditional baits used to attract cockroaches; all of these were observe in conjugate with the related public health aspects.

\section{METHODS}

This entomology survey on cockroach was a cross-sectional based-study, held during AugustDecember 2015, in a private faculty building and its surrounding located in a rapidly growing region of Cawang, east Jakarta. This three-story building built since 1973 and until now it is still used as a student campus. Everyday, hundreds of students and staffs conduct their regular- campus based daily activities inside this building.

Cockroach sampling were done using a modified plastic bottle with a single attractant for each bottle used, and the baits/ attractants used were as follow: brown sugar, peanut butter, chicken egg, chicken broth, shrimp paste (terasi), bread, banana, potato, boiled chicken liver and strawberry jam. All of the baits/ attractant were prepared in condition as human food. Baits were put in the floor of warehouse in the $1^{\text {st }}$ and $2^{\text {nd }}$ floor, student lab, drains, culverts and sewers and waste disposal wells. Baits used as cockroach trap were left overnight, at weekdays and weekend on the day that has been determined before, starting around $17.00 \mathrm{pm}$ and then collected very early in the next morning for further processing.

All of the cockroaches trapped were counted, and as the subjects of our investigations were living specimens of cockroach, and right before examination began, cockroach killed individually and anaesthetically using cotton contain ether that were put inside the baits. Killed cockroach examined under the dissecting microscope for identification using standard taxonomical keys. After the species identified, fresh preparations were made from the crushed whole body of cockroach by putting it inside a sterile $5 \mathrm{ml}$ tube with addition of some sterile water, then crushed mechanically with the tip of sterile tweezer. Tube contained cockroaches then spinned inside centrifugator in a low speed rotation 
for 5 minute. After centrifugation, the tube is removed and stagnated for a while, to let any possible parasite to come to the surface. Then from the upper part of the supernatan, carefully aspirated some amount of supernatant using sterile glass pippete, put it on top of an object glass, covered with cover glass then observed under light microscopy at magnification 100x and 400x, seeking for the presence of parasites. Slides were also contrasted and stained with standard staining: Lugol (for helminth egg or protozoan cyst), Eosin (for living protozoa) and $10 \% \mathrm{KOH}$ solution (for yeast). Examination were done under supervision of trained and experienced Parasitology lab technician and the final confirmation were made by the first author. all preparation of specimen and its examination were done in our laboratory at the department of Parasitology, faculty of Medicine, Universitas Kristen Indonesia.

All of the parasite, e.g. nematodes egg/larva, protozoan, or yeast that succesfully isolated were further studied for co-occurence with other parasite (if any), ounted for density and biometrical measurements. Pictures of the observed parasites were taken using a digital Camera or camera of phone cell. Data about temperature, humidity, location (including the presence of water, the $\mathrm{pH}$ of the water, and shelter) were also collected in each time we setting up a trap as supporting data. All data were then analyzed further using computerize.

\section{RESULT}

This study started on August and finished on December 2015. All baits were prepared and put in the location that already appointed by the 2 nd and 3rd author previously, and setting off the baits in the appointed location were located as close as possible to suspected hidden water sources, where cockroaches also suspected to exist. Because of some spot/location of baits were in relative open condition, baits only put in the appointed location after office hours to avoid the potency of baits getting ruin/disturbed by human activity, unintentionally. The second and third authors optimized in advance the methods, step by step, and alaso try to determine the types of bait and the form of cockroach trap, until they obtained the most satisfactory model for the whole study.
Supporting data of location, in general, where our baits sucessfully trapped the cockroaches as follow: temperature ranging from 20.1 to $35{ }^{\circ} \mathrm{C}$, where most cockroaches were tend to be caught at higher temperature $\left(>30.1^{\circ} \mathrm{C}\right)$, in dark / minimal light condition and humidity ranging from $61-98 \%$ (most were trapped in range $61-80 \%$ humidity) and $\mathrm{pH}$ $>7$.

Our four months sampling successfully trapped 434 cockroaches; all belongs to the species $P$. americana, which consist of $294 \operatorname{nimf}(67,7 \%)$ and 140 adult cockroach $(32,3 \%)$. All of the cockroaches caught with the type of baits that are mentioned before; we were not able to caught cockroach from warehouse in the 1st and 2nd floor, student lab and canteen/cafetaria. Number of cockroach trapped using our baits were varied according to the type of baits.

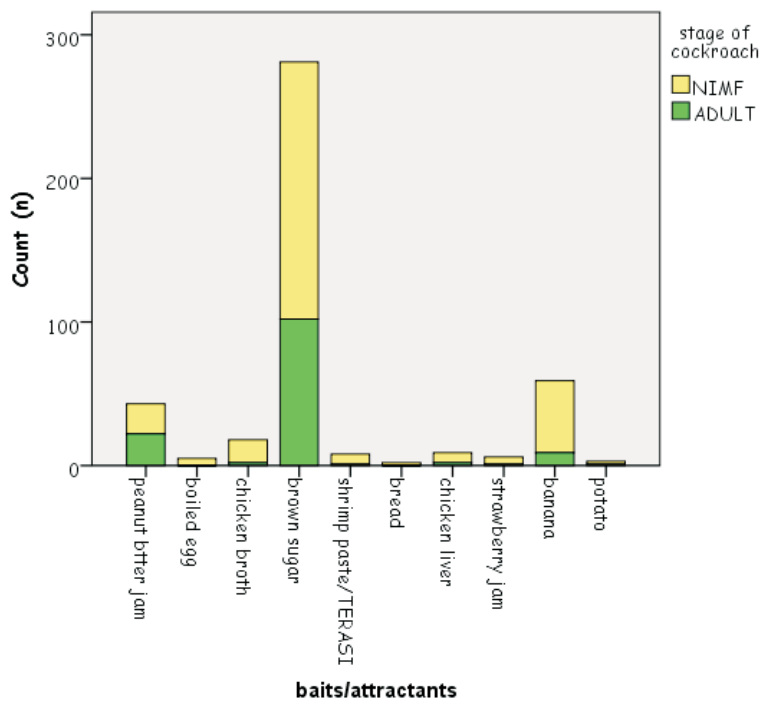

Figure 1. cockroach stage that were trapped using baits/ attractants

In figure 1, we presented number of cockroach caught based on the type of attractants. Most cockroaches were attracted to brown sugar $(\mathrm{n}=281 /$ $64,7 \%)$, followed by banana $(n=59 / 13,5 \%)$ and peanut butter jam $(n=43 / 9,9 \%)$. Eventhough that entomology-theoretically there is no difference between adult and nimf stage on preference to the type of attractant but our findings showed us that more adult stage attracted to brown sugar $(70.2 \%$ adult vs $60.9 \%$ nimfs) and peanut butter $(15.7 \%$ 
adult vs $8.6 \%$ nimf). While other type of baits, e.g banana (17.0\% nimf vs $6.4 \%$ adult ), chicken broth ( $6.6 \%$ nimf vs $1.4 \%$ adult), terasi ( $2.3 \%$ nimf vs $0.7 \%$ adult), chicken liver ( $2.3 \%$ nimf vs $1.4 \%$ adult), chicken egg ( $2 \%$ nimf vs $0 \%$ adult), strawberry jam ( $2 \%$ nimf vs $0.7 \%$ adult), potato ( $0.8 \%$ nimf vs $0.7 \%$ adult) and bread ( $0,8 \%$ nimf vs $0 \%$ adult) attract more nimf than adult stage.
Statistically, using Pearson chi-square test, there is a correlation between the stage of cockroach (adult vs nimf) with the baits type ( $p=0.002)$.

In the following table, we showed crosstabulation between stage of cockroach (nimf or adult) against type of parasite isolated (no parasite, single parasite or multiple parasite as shown in table. $1)$.

Table 1. The result of Parasite identification from cockroaches trapped using baits

\begin{tabular}{|c|c|c|c|c|}
\hline \multirow{2}{*}{$\begin{array}{l}\text { Type of } \\
\text { parasite }\end{array}$} & \multirow[t]{2}{*}{ Identification } & \multicolumn{2}{|c|}{ Stage of development } & \multirow{2}{*}{$\begin{array}{c}\text { Total } \\
(n=434)\end{array}$} \\
\hline & & $\operatorname{nimf}(n=294)$ & $\operatorname{adult}(n=140)$ & \\
\hline none & No parasite found & $78(26.5 \%)$ & $18(12.8 \%)$ & $96(22.1 \%)$ \\
\hline \multirow{3}{*}{$\begin{array}{l}\text { Single } \\
\text { parasite }\end{array}$} & Entamoeba coli & 0 & $3(2.1 \%)$ & $3(0.6 \%)$ \\
\hline & Hookworm egg & $16(5.4 \%)$ & $10(7.1 \%)$ & $26(5.9 \%)$ \\
\hline & Worm larvae (unidentified) & $10(3.4 \%)$ & $14(10 \%)$ & $24(5.5 \%)$ \\
\hline \multirow[t]{7}{*}{$\begin{array}{l}\text { Multiple } \\
\text { parasite }\end{array}$} & $\begin{array}{l}\text { E. coli, Worm larvae } \\
\text { (unidentified) }\end{array}$ & $1(0.2 \%)$ & $3(0.7 \%)$ & $4(0.9 \%)$ \\
\hline & $\begin{array}{l}\text { Worm larvae and egg } \\
\text { (unidentified) }\end{array}$ & 0 & $1(0.2 \%)$ & $1(0.2 \%)$ \\
\hline & $\begin{array}{l}\text { Worm larvae, ciliata } \\
\text { (unidentified) }\end{array}$ & $9(2 \%)$ & $9(2.1 \%)$ & $18(4.1 \%)$ \\
\hline & $\begin{array}{l}\text { Worm larvae (unidentified), } \\
\text { hookworm egg }\end{array}$ & $61(14 \%)$ & $40(28.5 \%)$ & $101(23.3 \%)$ \\
\hline & $\begin{array}{l}\text { E. coli, E. histolytica, } \\
\text { Hominis }\end{array}$ & 0 & $4(0.9 \%)$ & $4(0.9 \%)$ \\
\hline & $\begin{array}{l}\text { E. coli, E.histolytica, Worm } \\
\text { larvae (unidentified) }\end{array}$ & $119(40.4 \%)$ & $2(0.5 \%)$ & $121(27.9 \%)$ \\
\hline & $\begin{array}{l}\text { E. histolytica, Worm larvae and } \\
\text { egg (unidentified), hookworm egg }\end{array}$ & 0 & $36(8.3 \%)$ & $36(8.3 \%)$ \\
\hline Total & & $294(67.7 \%)$ & $140(32.3 \%)$ & $434(100 \%)$ \\
\hline
\end{tabular}

We found 338 cockroach contain parasite $(77.9 \%)$ and $96(22.1 \%)$ were clean/sterile. Species of parasite isolated were as follows: E. coli, $E$. histolytica, B. Hominis, Worm larvae and egg (unidentified), hookworm egg, and also egg from the class of ciliata (unidentified). And from those 338 cockroaches, $53(15.4 \%)$ contain only single species of parasite, and from the rest 289 
cockroaches or $(85.5 \%)$ we were able to isolate multiple parasite in different combination.

Table 1 showed us that more nymphs were not containing parasites compare to adult stages of cockroaches ( 78 or $18,0 \%$ adult vs 18 or $4,1 \%$ nimf). The reason for that was probably because the adults were more active, especially in searching food, so they were more likely to be exposed to the parasite. In the single infection group, we isolated helminths (egg or larvae) more than protozoa. But in the multiple infection group, protozoan more isolated than helminths.

Statistical analysis using Pearson Chi-square showed us that there is a correlation between stage of cockroach and the type of, and also with the density, of parasite isolated. ( $p=0.000$ and $p=0.000)$.

\section{DISCUSSION}

This 4 months of entomological survey taught us several aspects on the vectorial capacity and its potential of transmitting infectious intestinal disease. It seems that our finding confirmed the result of several other studies. Shahrarki et $a l^{8}$ in Iran pointed out the close encounter of this insect with human; especially in homes or buildings where human activity is high. Urban areas is one of human factor which affect the distribution and even expansion in number and species of cockroaches. This should raise our concern on the community/ public health aspect of the existence of cockroaches inside houses or buildings.

Other important enviromental factors that needed for its growth is temperature. The range of temperature in our findings was 20.1 to $35^{\circ} \mathrm{C}$ with the average $30.1^{\circ} \mathrm{C}$. Murdock et $a l^{9}$ argued that environmental factors (e.g temperature) also have strong impact on insect immunity and it might influence the outcome of host-parasite interactions. This environmental factors also have their own variability that can influences both vector immunity and the micro-organism itself, and in the end will interact with the host factor. This dynamic interaction indicated that vectors, micro-organisms and the hosts were all associated in a dynamic and variable world. This also happened to other enviromental factors, e.g humidity.
Baits/ attractants used in our study were prepared as in human food condition. Our team succesfully trapped cockroaches using all kind of baits/ attractants, it shows that cockroach attract to all kind of human food, brown sugar is the most attractive baits. It will be interesting to further explore the active compound of this brown sugar and or peanut butter which attracts this insects. The mechanism of action of the attractants along with the question of why is there any difference on preferences to attractants/ baits between stage (adult vs nimf) or even gender (male vs female) cockroach are still big future research questions need to be answer. ${ }^{7-9}$ Those future research questions is very important and prospectfull in terms of natural insecticidal development. Our result on the effectiveness of brown sugar as baits showed us its potency for future development of insecticide. Considering that nowadays, people are turned their attention and also selection more on to natural product, rather than to chemical-artificial product. The prospect selling of natural based products is crystal clear and promising. Natural based products usually brings along issues of healthier ( to the user from community medicine point of view), less contaminating (to the environment), more acceptable (to the society) and probably cheaper in price compare to artificial chemistry-based product. ${ }^{5,15,16}$

Other aspect of our result taught us something (again) on the potency of food contamination caused by cockroach. ontamination usually occurs in foods that are not covered or left open for some time.Because all of the baits in our study use compounds prepared in condition as of human food, the result of our study taught us that any kind of human food have the potential to attract cockroach, eventhough it seems that cockroach focused more on brown sugar. So, people must be carefully handle and manage their food, especially those fresh and ready to eat food. ${ }^{10-13}$ If one desire to keep those 'ready to eat food' for some time before he/she ate it, he/she or anyone who handle that food must make sure with the cockroach-free condition in the storage location. ${ }^{13,14}$ It is more advisable to eat fresh and ready to eat food as soon as possible. ${ }^{15,16}$

Isolation of the parasite were perform from crushed part of the whole body of cockroach (means that it come from the outer and inner part). Without 
distinction of the source of isolation (inner or outer part of cockroach) it will be difficult to determine wether the parasite isolated from cockroaches in our study was accidentally stick to the body (outer part) or also ingested by the cockroach together with the food (found inside its GI tract/inner part). It will be very interesting to examine further in order to determine wether the parasite isolated were from the outer or inner part of the cockroach and also to investigate the source to find out the density of the parasite in its natural location. Further more, evaluating their pattern of susceptibility to antibiotics (bacteria) or other relevant anti-microbes (anti-protozoa or anti-fungus) is also urgent from the community and environmental health aspect. ${ }^{1}$

The public health implication of this finding is the awareness wether these cockroaches also found in the canteen/cafetaria and how their possible connection with the cafetaria personnel or food handler. Cafetaria or canteen considered as contamination-vulnerable and if these insect was isolated there, it would have the opportunity to contaminate food or water source. In the context of our study site, the canteen/cafetaria, as well as the lab has been cleaned regularly (especially during office hours) using commercial hygiene-cleaners products and with the availability of janitors/ cleaning service personnel who are on duty to maintain, or in charge of, ensuring the room was kept clean. Our result confirmed the effectiveness of our continously sanitation programme to get rid of the insect from the cafetaria/canteen or other places that must be maintain insect-free. ${ }^{8}$ The consistency of these sanitation efforts that make the number of insects (e.g cockroach) under control. ${ }^{20}$ Controlling the number means reduce the possibility of exposure. ${ }^{8,20}$

Cockroach was long known as mechanical vector of several intestinal parasite, including for protozoa and helminth. ${ }^{1-3,6-8,10,12-14,18}$ This means that the parasites were attach to the outer body part of the cockroach and can be carry away and contaminated food or water un-intentionally. Unintentionaly, because when a cockroach goes around in its own quest for food/food seeking behaviour, it is likely that the cockroach contaminates the food. Unfortunately, some studies on cockroaches also able to isolate those parasite from the inner part of the cockroaches, especially from its GI system. This should make people more aware that contamination of the water or food not just merely took place by mechanical means but also biologically thru anterior or posterior-end product of these cockroaches. Evaluating the composition or mixture of density of intestinal parasite, or where these parasite reside inside the body of cockroach might reveal the potency or ability of this insect to spread potential disease to human. Beside infection, cockroach product are strong allergen which can also trigger allergy in atopy individuals, and evaluating for possible relationship between infection and allergy due to cockroach might revealed the other role of this insect on human disease. ${ }^{20}$

\section{CONCLUSION}

The prevalence of parasite (protozoa and helminth) isolated from cockroach was $77.9 \%$ and with its preference to brown sugar baits. From the public health perspective, these findings should make us more aware of the potential of diseases that can be caused by cockroach and how important to keep and maintain the status of personal hygiene and environmental sanitation.

\section{ACKNOWLEDGMENT}

The authors would like to thank Mr. Urip Susiantoro for all sample preparation and to Mr. Ali for helping to prepare and collecting all the baits/ attractants. Some part of this research fund comes from donors who are alumni of FKUKI.

\section{REFERENCE}

1. Sarwar M. Insect vectors involving in mechanical transmission of human pathogens for serious diseases. Intl J Bioinformatics Biomed Eng. 2015; 1(3):300-6

2. Alzain B. Cockroaches: Transmission of medically important parasites. ARPN J Sci Technol. 2013;3(5):533-7

3. El-sherbini GT, El-Sherbini ET. The role of cockroaches and flies in mechanical transmission of medical important parasites. J Entomol Nematol. 2011; 3(7): 98-104 
4. Anonymous. Cockroaches: Unhygienic Scavengers in Human Settlements. (n.d.). 1 st ed. [ebook] World Health Organization, pp.288-299. Available at: http://www.who.int/ water_sanitation_health/resources/ vector288to301.pdf

5. Nalyanya G, Liang D, Kopanic, Jr. RJ, Schal C. Attractiveness of Insecticide Baits for Cockroach Control (Dictyoptera: Blattellidae): Laboratory and Field Studies. J. Econ. Entomol.2001; 94(3): 686 Đ693

6. Etim SE, Okon OE, Akpan PA, Ukpong GI, Oku EE. Prevalence of cockroaches (Periplanata americana) in households in Calabar: Public health implications. J of Publ Health Epid. 2013; 5(3): $149-52$

7. Iboh CI, Ajang RO, Etta HE, Abraham JT. Public health implications of cockroaches within households in Calabar municipality, Cross River State, Nigeria. Glob J Publ Health Epidemiol. 2015; 2 (2): 114-9

8. Shahraki GH, Parhizkar S, Nejad ARS. Cockroach Infestation and Factors Affecting the Estimation of Cockroach Population in Urban Communities. Intl J Zool. 2013, Article ID 649089. http://dx.doi.org/10.1155/2013/649089

9. Murdock CC, Paaijmans KP, Cox-Foster D, Read AF, Thomas MB. Rethinking vector immunology: the role of environmental temperature in shaping resistance. Nat rev Microbiol. 2012; 10:869-76

10. Oyeyemi OT, Agbaje MO, Okelue UB. Foodborne human parasitic pathogens associated with household cockroaches and houseflies in Nigeria. Parasite Epidemiol Control.2016;1:103

11.Carrell JE, Tanner EM. Sex-Specific Food Preferences in the Madagascar Hissing Cockroach Gromphadorhina portentosa (Dictyoptera: Blaberidae) J Insect Behavior 2002;15(5): 707-14

12.Solomon F, Belayneh F, Kibru G, Ali S. Vector Potential of Blattella germanica (L.) (Dictyoptera: Blattidae) for Medically Important Bacteria at Food Handling Establishments in Jimma Town, Southwest Ethiopia. BioMed Res
Intl. 2016, Article ID 3490906, http://dx.doi.org/ $\underline{10.1155 / 2016 / 3490906}$

13.Bala AY, Sule H. Vectorial Potential of Cockroaches in Transmitting Parasites of Medical Importance in Arkilla, Sokoto, Nigeria. Nigerian J Basic Appl Sci. 2012; 20(2): 111-5

14. Malik K, Jamil A, Arshad A. Study of Pathogenic Microorganisms in the External Body Parts of American Cockroach (Periplaneta americana) Collected from different Kitchens. IOSR Journal of Pharmacy and Biological Sciences (IOSRJPBS). 2013; 7(6):45-8

15.Tee HS, Lee CY. sustainable cockroach management using insecticidal baits: formulations, behaviour response, and issues. In Dhang P. (ed). Urban insect pests: sustainable management strategies. CAB international. 2014; Pp 65-85

16.Liang D. Performance Of Cockroach Gel Baits Against Susceptible And Bait Averse Strains Of German Cockroach, Blattella germanica (Dictyoptera : Blattellidae) - Role Of Bait Base And Active Ingredient. Proceedings of the Fifth International Conference on Urban Pests. ChowYang Lee and William H. Robinson (editors), Printed by Perniagaan Ph'ng @ P\&Y Design Network, Malaysia 2005.

17.Mullins DE. Nitrogen metabolism in the american cockroach: an examination of whole body ammonium and other cations excreted in relation to water requirements. J Exp Biol. 1974; 61: 54I-56

18.García F, Notario MJ, Cabanás JM, Jordano R, Medina LM. Incidence of Bacteria of Public Health Interest Carried by Cockroaches in Different Food-Related Environments. J Med Entomol. 2012; 49(6):1481-4

19.Ifeanyi OT, Odunayo OO. Microbiology of Cockroaches - A Public Health Concern. Intl J Scient Res. 2015; 4(4):485-7]

20.Portnoy J, Chew GL, Phipatanakul W, Williams PB, Grimes C, Kennedy K, et al. Environmental assessment and exposure reduction of cockroaches: A practice parameter. J Allergy Clin Immunol. 2013 October ; 132(4): . doi:10.1016/ j.jaci.2013.04.061 
21.Al-Fattly HHH, Al-Aridhi HS. Antibiotic resistant bacteria associated with the cockroach Periplaneta americana in Al-Diwaniya city / Iraq. Intl J Adv Res. 2014; 2(12): 709-14

22.Oudin A, Richter JC, Taj T, Al-Nahar L, Jakobbson K. Poor housing conditions in association with child health in a disadvantaged immigrant population: a cross-sectional study in Rosengård, Malmö, Sweden. BMJ Open. 2016;6:e007979. doi:10.1136/ bmjopen-2015007979
23.Ejimadu LC, Goselle ON, Ahmadu YM, JamesRugu, NN. Specialization of Periplaneta Americana (American Cockroach) and Blattella Germanica (German cockroach) Towards intestinal parasites: A Public Health Concern. IOSR Journal of Pharmacy and Biological Sciences (IOSR-JPBS). 2015; 6(IV):23-32 